\title{
Study of Supply Chain Coordination Contract Model based on Rough Set and Markov Chain
}

\author{
Hailan Ran \\ Xi’an Fanyi University, Xi’an, Shaanxi, 710105
}

Keywords: Rough Set; Markov Chain; supply chain

\begin{abstract}
In this paper, the Markov Chain is trained using the extended Rough Set of hidden layer information to simplify the basic indicator data, and an improved method based on index training information reduction and Rough Set training is constructed by superimposing different time series. The application results show that supply chain companies mainly rely on their own production and accumulation in production scale to obtain collaborative management performance. The key point of improving supply chain collaborative management performance lies in information sharing.
\end{abstract}

\section{Introduction}

The logistics service supply chain is based on logistics service integrators, integrates logistics service resources with advanced information technology, provides personalized, integrated and networked logistics services for logistics demanders, and provides logistics services for manufacturing supply chains. New supply chain. With the development of economic globalization, market competition has become increasingly fierce, and customer demands have also shown diversified development trends. Uncertainty in social needs has greatly increased. The competition of modern enterprises has surpassed the competition among individual enterprises, and how to make the entire supply Companies in the chain gain competitive advantage in new environments and become the focus of research by companies and scholars. Faced with an increasingly competitive environment, only through strict accounting and effective evaluation of supply chain performance can we provide a reliable basis for corporate management decisions, so that corporate resources and social resources can be reasonably and effectively configured to help enterprises successfully implement strategies [1]. To gain a competitive advantage. However, most of the traditional performance evaluation methods are static evaluations, neglecting the randomness and uncertainty in the dynamic development of the supply chain. Therefore, how to choose a scientific and reasonable evaluation method has become a problem to be solved in the supply chain research.

There are many deficiencies in the existing research literature on supply chain performance evaluation. This paper proposes to use fuzzy assessment and Markov forecast to study the dynamic performance of logistics service supply chain. First, by improving the product quality function configuration (QFD) model, considering the impact of customer demand on the logistics service supply chain performance evaluation index, constructing an improved QFD model, calculating the evaluation index weights, and using fuzzy assessment to different historical periods of logistics service supply chain performance Secondly, combining with the historical evaluation results, based on the forecast theory of Markov chain forecasting logistics service supply chain status development trend, and give logistics service supply chain performance improvement direction; Finally, combined with examples to test the conclusions of this paper.

\section{Principles of Performance Evaluation of Supply Chain Collaboration Management}

For problems with multivariate interactions and cumulations, it is usually a simple stratified correlation measure. In fact, if the selected metrics interact in addition to one another, the accumulated effects of different action levels need to be taken into account. For the solution of such problems, the sub-attribute vector sets of rough sets should be classified according to the upper and lower layers. Assume that the performance of supply chain collaboration management is selected 
according to the collaboration performance and collaboration associations. The set of an overall vector set interpretation goal is the cooperative management effect, then its corresponding sub-attribute set is L(A). Set up a logical description map that matches the same level of supply chain collaboration management as a sample vector set. Then the mapping and setting conditions $\mathrm{X}$ $=\mathrm{c}(\varphi)$ (whether the supply chain collaboration management level is different from the different levels), Then the corresponding supply chain collaboration management partitions the vector set according to the basic rough set [2].

In this paper, we will select indicators for information superposition and filtering operations, and divide the error relative value partitions in rough set training to Markov's discrete sequence transition probabilities, and then use a certain amount of post-transition probability partitions to perform rough set vector set training. Get assessment accuracy at different stages of supply chain collaboration management. Firstly, the state corresponding to the vector set is divided according to the interval, the basic data input of the supply chain selection index is formed in the different layers, and the overlapping part information is used as the basic data of the preselected hidden layer information of the rough set to extend the index basic data. Hierarchical signal is used as the basic set of fitting precision of rough vector set training. According to this set value, the training of intermediate links is carried out. Then through the training output of BP framework, information superimposed interval can be deleted according to the basic form of supply chain cooperation management. Finally, the significant signal in training is used to initialize the measurement index and training sequence to form a supply chain collaboration management index evaluation matrix that is consistent with the basic node checking. For different decision-making measures in the supply chain collaboration management process and supply chain operations, this paper will practice morphology in the form of indicators selected for fixed-line speech, in order to facilitate the implementation of its management methods to estimate data.

\section{Improved Rough Set and Markov Chain Supply Chain Effects}

Based on the above analysis, this paper combines the actuality of the supply chain collaboration management process and combines the upstream and downstream enterprises in the supply chain of xx provinces [3]. Three aspects of operational capability, collaboration capability, and operational capability are selected as indicators for measuring the collaborative management performance of the supply chain. Operational capabilities include supply chain cash flow rate and output value growth; collaboration capabilities include supply chain team information sharing and cross-sectoral collaboration. Occurrence; operational capabilities include the company's frequency of repeat orders and customer retention. The indicators of operational capabilities in the selected indicators consist of capital turnover rate and output value growth. They are based on the relative ratio of the previous year to the previous year. Combined with the above analysis, the supply chain collaboration management performance a1 is based on the capital turnover rate a11. The grades are set to $0.8,0.5$, and 0.3. For the sake of consistency, the remaining indicators are set to three categories of supply chain performance management cooperation, which, the output growth rate of a12 corresponding to $2 \%$ or less, $2 \%$ to $3 \%, 3 \%$ or more; The first-level indicator collaboration ability a2 mainly includes the team information sharing a21 and the cross-department collaboration quantity a22, which is based on the annual conversion in the supply chain collaboration management process, and combines the sample reality to share information and cross-departmental collaboration. The amount of occurrence is divided into 0 to 4 times, 5 to 10 times, and 10 or more third gears. The first-level indicator capability a3 includes the frequency of repeated orders a31 (calculated by year), and the customer retention a32 (by The calculation of the number of households) respectively set the third gear to be 0 2 times, 3 5 times, 5 times or more, $0 \sim 1$ household, 2 4 households, 5 households and 5 households or more. Among them, the cash flow rate data is derived from the company's assets and business accounts for the sample, and the remaining information is compiled from the annual work plan, project implementation data, company order information management platform, and customer data files provided by the sample data department [4].

The selected secondary indicators basically show a high sample at the middle level and a low 
sample distribution at both ends. That is to say, the overall supply chain collaboration management performance is relatively high in the sample of the intermediate level of operational capability, collaboration, and operational capability. Supply chain collaboration management decisions with better or poorer operational capabilities, collaboration capabilities, and operational capabilities are relatively scarce. Among them, the best distribution number of the single order secondary indicators of the repeated order frequency is too few, only 11 and the worst is 33, which is the most distributed, indicating that the supply chain decision management is in the order, that is, repeated business There is insufficient performance in the competitiveness. The selection of secondary indicators differs in explaining the performance of supply chain collaboration management of the primary indicators. There are excellent, good, fair, and bad levels, and only two secondary indicators (financial turnover rate and output value growth) in the selected sample are used to modify the first-order indicators. Rough sets of vector indicators can be interpreted as excellent results of decision-making. This reflects that at the current stage, the key way for China's vast supply chain companies to obtain management performance is still their own production and cumulative gains in terms of production scale. However, in this process, for some of the company's own internal collaborative management and operation management, The results of general, better, and worse, general managerial performance decisions are shown, reflecting the fact that supply chain collaboration management has not been directly and effectively integrated with the company's own management in the course of business operations. The second-level indicators - the sharing of team information and the amount of cross-department collaborations - are all measured from the point of view of the management of supply chain companies. Therefore, the verification results show that for the majority of supply chain companies, they are doing a good job in the supply chain. While improving performance, we should go further from teamwork and information sharing mechanisms. Grab a breakthrough to achieve management performance information on the content management interoperability level of improvement [5].

After Markov modified rough set training reduction vector set data, it undergoes a total of 80 trainings, which gradually entered the stationary phase at the 45th time, and essentially feedbacks the termination of the selected sample training. According to this result, the Markov chain is Performance normalized input training, re-entry sample data of the above formula is set as training optimal feedback signal, there are two groups of four secondary indicators in the reduced Markov vector set, and the feedback of the vector within the rough set of wind level is reported. Strong signals, which are team information sharing (times/year), cross-department collaborations (times/years), frequency of repeat orders (times/years), customer retentions (households), and output signals organized according to the Markov chain are $(0.00210 .9912-0.00110 .0067)$ and (0.0039 0.0812-0.0020 0.0039), except that the cross-department collaboration deviated from the cross-functional role that corresponds to operations and collaboration, and the remaining secondary indicators provide feedback on the supply chain management performance of the primary indicators. All correspond to the same order of magnitude. At the same time, the output error of the Markov vector rough set based on (11) is obtained according to the output vector in the feedback of the vector set information obtained by the improved rough set training.

The turnover rate of a11 has shown relatively stable characteristics of fluctuations in the selection index during the supply chain collaboration management process in the past ten years. It basically revolved around the A-level and B-level oscillations. Similarly, the growth rate of output value a12 is similar to this. The year-by-year cumulative effects of the interactions in supply chain collaboration management selection indicators are stable, and capital turnover and output value growth are the main channels for supply chain collaboration, while the second-level indicators, collaboration capabilities, are promoted through year-by-year supply chain collaboration. The limited improvements have been achieved, especially the sharing of the second-level indicator team information a21, which has not yet played a role in promoting the collaborative management of supply chains on the cumulative effects. This is also a lack of information sharing in the entire supply chain system in China at this stage. In response to the implementation of such responses, the cumulative effect of the third-order tier-one indicator, operational capability a3, on the overall time 
series is low, indicating that the supply chain collaboration management performance has relatively few driving factors, and it has further reduced collaboration within various systems. , Team sharing failed to more effectively and directly form supply chain collaboration management capabilities. It can be seen that although some of the elements exist with the interrelated structural characteristics of collaborative management of the overall supply chain, the cumulative process within the entire time series has not yet reached the point of coordination with supply chain collaboration management, which is also the key to the improvement of supply chain collaboration management.

\section{Conclusion}

Supply chain performance evaluation is the measurement of the degree of realization of the supply chain goals, and it is of great significance to provide decision-makers with support for business decision-making. This paper studies the dynamic performance evaluation of logistics service supply chain, and draws the following conclusions: a) Using the improved QFD model to study the method of calculating the weight of performance evaluation index of logistics service supply chain, and improving the subjective influence of the AHP method relying solely on expert scoring. In the calculation of weights, the importance of customer demand to the performance evaluation of logistics service supply chain is fully considered. b) Combine the operational level of the logistics service supply chain, formulate a reasonable evaluation index grading standard, design the membership function of different indicators, establish the fuzzy relation matrix of the performance evaluation of the logistics service supply chain in each historical period, and use the fuzzy evaluation method to calculate the logistics service The comprehensive evaluation of performance of supply chain in different historical periods. c) Use Markov chain forecasting theory to evaluate the expected performance of logistics service supply chain, and provide improvement measures for different service levels of the logistics service supply chain to provide theoretical support for decision-making.

\section{Acknowledgements}

Research project: Xi’an Fanyi university education quality project (quality course) No. Z1307

\section{References}

[1] Mentzer J T, Dewitt W, Keebler J S, et al. Defining Supply Chain Man-agement[J]. Journal of Business Logistics, 2001, 22(22).

[2] Bai C, Dhavale D, Sarkis J. Complex Investment Decisions UsingRough Set and Fuzzy C-means: An Example of Investment in GreenSupply Chains[J]. European Journal of Operational Research, 2015, 248(2).

[3] Tiwari S, Roy S S, Viswanatham V M. Using Rough Sets for Optimal Cost Evaluation in Supply Chain Management [J]. International Conference on Computing, 2012.

[4] Zou Z, Tseng T L, Sohn H, et al. A Rough Set Based Approach to Dis-tributor Selection in Supply Chain Management[J]. Expert Systems with Applications, 2011, 38(1).

[5] Xie Lijuan. The Restructuring of Circulation Organizations in the Internet Era: A Perspective of Reverse Integration of Supply Chains [J]. China Industrial Economy, 2015, (4). 